\title{
Decreased Pigmentation
}

National Cancer Institute

\section{Source}

National Cancer Institute. Decreased Pigmentation. NCI Thesaurus. Code C161560.

Decrease in the amount of pigment. 